\title{
MULTILETRAMENTOS E PRÁTICAS DE LEITURA, ESCRITA E ORALIDADE NO ENSINO DE LÍNGUA PORTUGUESA NA EDUCAÇÃO BÁSICA
}

\author{
Úrsula Cunha Anecleto ${ }^{1}$ \\ Josimara Divino Oliveira Miranda ${ }^{2}$
}

\begin{abstract}
Resumo. Este artigo discute sobre práticas de leitura, escrita e oralidade no ensino de Língua Portuguesa, tendo como enfoque o gênero narrativa fílmica. Para isso, partiu-se da concepção de eventos de letramento e da multiplicidade semiótica de constituição dos textos presentes nas práticas discursivas do mundo moderno, de forma multimodal, a partir da interação entre imagem, texto, sons e outros elementos que constituem as interações cotidianas. Nessa perspectiva, o ato de ler e de produzir textos orais e escritos é resultado da articulação de diferentes ordens discursivas, fomentadas pelo hibridismo da linguagem e pelos multiletramentos.
\end{abstract}

Palavras-chave. Ensino de Língua Portuguesa. Multiletramentos. Narrativa fílmica.

\section{MULTILETRAMENTS AND PRACTICES OF READING, WRITING AND ORALITY IN PORTUGUESE LANGUAGE EDUCATION IN BASIC EDUCATION}

\begin{abstract}
This article discusses practices of reading, writing and orality in the teaching of Portuguese Language, focusing on the genre film narrative. For this, it started from the conception of literacy events and the semiotic multiplicity of the constitution of the present texts in the discursive practices of the modern world, in a multimodal way, from the interaction between image, text, sounds and other elements that constitute the daily interactions. In this perspective, the act of reading and producing oral and written texts is the result of the articulation of different discursive orders, fomented by the hybridity of language and by multiliteracies.
\end{abstract}

Keyswords. Portuguese Language Teaching. Multiliteracies. Film Narrative.

\footnotetext{
${ }^{1}$ Doutora em Educação (UFPB), na linha de pesquisa Estudos Culturais. Mestra em Crítica Cultural (UNEB), na linha de pesquisa Letramento, Identidade e Formação Docente. Graduada em Letras Vernáculas (UEFS). Professor Assistente no curso de Letras Português na Universidade do Estado da Bahia (UNEB/campus XIV). Professora coordenadora do projeto de extensão Letramento e Ensino. Endereço eletrônico: ursula.cunha@hotmail.com.

${ }^{2}$ Graduanda do curso de licenciatura em Letras Português pela Universidade do Estado da Bahia (UNEB/Campus XIV). Bolsista do projeto de extensão Letramento e Ensino. Endereço eletrônico: josimaradivino@hotmail.com.
} 


\section{Introdução}

O ensino de Língua Portuguesa, em todos os níveis de escolarização, deve ter como enfoque atividades de leitura, escrita e oralidade que façam parte não apenas do universo escolar dos sujeitos, mas também de sua vida cotidiana. Nesse sentido, espera-se que a ação docente centre-se em práticas de letramento, que são constituídas, linguisticamente, a partir de práticas sociais (STREET, 2014). Letramento é um conceito criado para referir-se aos usos da língua escrita não somente na escola, mas em diversas agências sociais, porque a escrita, na atualidade, faz parte da paisagem cotidiana. Assim, o conceito de letramento surge como uma forma de explicar o impacto da escrita em diversas esferas de atividades e não somente nas que fazem parte da rotina escolar.

Letramento, então, abrange o processo de desenvolvimento e o uso dos sistemas de escrita nas sociedades, refletindo em outras mudanças sociais e tecnológicas. Dessa forma, uma importante contribuição dos estudos do letramento para a reflexão do ensino da língua é a ampliação do universo textual, ou seja, a inclusão de novos gêneros, novas práticas textuais, a partir da combinação de diferentes modos de representações (imagens, músicas, cores, linguagem oral, linguagem escrita etc.) que, até pouco tempo, não eram tão valorizadas nas salas de aula. Dentre esses novos tipos textuais, destaca-se a narrativa fílmica.

Dessa forma, este texto tem por objetivo apresentar reflexões teórico-pedagógicas sobre prática de letramento realizada com alunos do 4 응 ano do Ensino Fundamental I, em uma escola pública do município de Conceição de Coité, no estado da Bahia, a partir de eventos de letramento subsidiados pela narrativa fílmica. A atividade, organizada a partir de uma sequência didática, faz parte do projeto de extensão Letramento e Ensino, realizado pela Universidade do Estado da Bahia (UNEB), em parceria com a Secretaria do Município. 


\section{Multiletramentos e ensino}

Na perspectiva de convergência semiótica, o ato de ler e de produzir textos (orais e escritos) é resultado da articulação de diferentes ordens discursivas, fomentadas pelo hibridismo da linguagem, ou seja, pelos multiletramentos que fazem parte das práticas sociais, culturais, econômicas etc. dos sujeitos em suas comunidades. Nesse sentido, em uma sociedade letrada, a escrita se tornou um fator de interação entre as pessoas e a leitura uma forma eficaz de entendimento do mundo. No entanto, essas práticas socioculturais devem ser vistas como formas de garantir desenvolvimento interacional e cognitivo dos sujeitos (BAZERMAN, 2007). E é por isso que se torna necessário que a escola, como uma das agências mediadoras das práticas letradas entre o discente e o meio social, instaure novas funções, que visa à autonomia de seus alunos, através de seus discursos e enunciações, ampliando, dessa forma, suas potencialidades de aprendizagem.

Para Sousa (2004), a escola, na atualidade, não pode ignorar todo o potencial em relação à cultura, saber, interesse, necessidade e possibilidade de leitura e de escrita que a enorme diversidade dos seus alunos lhe apresenta. Então, é importante que as instituições educativas dialoguem com a diversidade de textos que circulam socialmente e fazem parte do universo de leitura de seus alunos, ou seja, que reconheçam a diversidade de práticas de letramento nas quais esses sujeitos estão inseridos.

Kleiman (2005, p. 6) assegura que a ideia de "letramento surge como uma forma de explicar o impacto da escrita em todas as esferas de atividades e não somente nas atividades escolares". Essa ideia deixa claro que, nas sociedades industrializadas, a escrita faz parte de diversas situações do cotidiano da maioria das pessoas, não apenas em sala de aula. Assim, o letramento representa um processo de aprendizagem social e histórica da leitura e da escrita, apresentadas de forma multissemiótica; pressupõe um conjunto diversificado de práticas sociais situadas que envolvem sistema de signos (como a escrita ou outras modalidades) para gerar sentido (ROJO, 2009).

Ser letrado, nessa perspectiva, "é participar de um conjunto de práticas sociais nas quais significados e sentidos de certos conteúdos 
codificados culturalmente (tradicionalmente, mas não exclusivamente, textos escritos) são gerados, disputados, negociados e transformados" (BUZATO, 2010, p. 53). O letramento apresenta consequências sociais e culturais que são coletivas e "abrange o processo de desenvolvimento e o uso do sistema da escrita nas sociedades, ou seja, o desenvolvimento histórico da escrita refletindo outras mudanças sociais e tecnológicas" (KLEIMAN, 2005, p. 21). A vista disso, torna-se essencial uma pedagogia dos multiletramentos na escola, que leve em conta "a multiplicidade cultural das populações e multiplicidade semiótica de constituição dos textos por meio dos quais ela se informa e se comunica" (ROJO, 2012, p. 13).

O conceito de multiletramentos aponta para dois aspectos essenciais ao entendimento das ordens discursivas na atualidade: a multiplicidade de linguagens, semioses e mídias que caracteriza os textos que circulam na contemporaneidade, e a multiplicidade cultural dos centros urbanos (ROJO, 2012). A multiplicidade cultural diz respeito às várias formas de produções culturais letradas em circulação na sociedade (CANCLINI, 2008), que representam um hibridismo textual, a partir da eliminação de fronteiras (letramentos dominantes e marginalizados; cultura popular e cultura erudita etc.), imbricadas mutuamente.

Devido a essa multiplicidade, torna-se necessário emergir uma nova ética discursiva (HABERMAS, 2012) e também outras estéticas, que surgem das multiplicidades de linguagens, por meio das quais a sociedade tem se comunicado e se informado (ROJO, 2012). Essa multiplicidade de linguagens tem gerado a multimodalidade (ou multissemiose). Nesse sentido, figuram-se os multiletramentos, com novos textos que proporcionam novas leituras e novas inter-relações entre leitor, texto, mensagem, portador.

Os pressupostos básicos dos multiletramentos envolvem, desse modo, os letramentos midiáticos, digitais, visuais, críticos, científicos, que são incorporados aos letramentos convencionais (DIONÍSIO, 2005). Nessa perspectiva de convergência de práticas de letramentos, o ato de ler e de escrever é resultado da articulação de diferentes modalidades de linguagem, que perpassa pela palavra, imagem, movimento, sons, etc., isto é, pelo hibridismo da linguagem. Dessa forma, são requeridas, dos alunos, novas 
práticas de produção e de análise crítica enquanto sujeitos receptores desses textos.

Os multiletramentos envolvem, portanto, leitura e escrita de textos cuja dinâmica relaciona o som, o visual, o espaço e o gesto (COPE; KALANTZIS, 2000), proporcionando diversas formas de interação (leitor/produtor) com vários interlocutores (interfaces, mídias, texto/discurso, outros usuários). Apresentam características peculiares: são interativos e colaborativos; transgridem a relação de poder estabelecida; são híbridos, fronteiriços, mestiços (em termos de linguagem, modos, mídia) (ROJO, 2012). Essa nova conjuntura (multi)interativa e multitextual conduz à ideia de uma pedagogia dos multiletramentos.

Dessa forma, práticas multiletradas se originaram com "as mudanças sociais, culturais e tecnológicas advindas da era do ciberespaço. Com isso, o cidadão contemporâneo precisa tornar-se aberto à diversidade cultural, respeitar a pluralidade étnica e saber conviver on-line" (DIAS, 2012, p. 8), tendo em vista que, na atualidade, muitas construções culturais são um conjunto de textos híbridos de diferentes gêneros, campos e de produtores variados. Entende-se, então, que "são necessárias novas ferramentas - além das da escrita manual (papel, lápis, caneta, giz e lousa) e impressora (tipografia, imprensa) - de áudio, vídeo, tratamento de imagem, edição e diagramação" (ROJO, 2012, p. 21), a partir de novos eventos de letramento em sala de aula.

\section{Eventos de letramento}

Eventos de letramento podem ser entendidos como ocasiões em que, nas interações humanas, a língua escrita está presente e exerce algum papel em diversas práticas sociais. Emergem das práticas de escrita e são definidas por elas (BARTON; HAMILTON, 1998). São “[...] situações em que a escrita constitui parte essencial para fazer sentido da situação, tanto em relação à interação entre os participantes como em relação aos processos e estratégias interpretativas" (KLEIMAN, 2008, p. 40). 
Assim, diversos eventos de letramento do cotidiano dos alunos, muitas vezes não valorizados no universo escolar, devem fazer parte da sala de aula, o que possibilitaria que esses sujeitos interligassem e reinterpretassem suas ações letradas cotidianas às da cultura escolar. Nesse sentido, o ensino de Língua Portuguesa, que apresenta como uma de suas finalidades criar e recriar situações que permitam ao aluno participar efetivamente de práticas de letramento (não apenas as escolares), pode ser estruturado a partir de um modelo ideológico de letramento, valorizando a linguagem como um produto cultural, social e historicamente situado (BRASIL, 1997) e sua diversidade de ordens discursivas.

\section{Letramento modelo autônomo e letramento modelo ideológico}

Práticas de letramento presentes em diversas agências sociais podem ser vistas a partir de dois enfoques: modelo autônomo e modelo ideológico (STREET, 2014). A abordagem do modelo autônomo vê o letramento tecnicamente, tratando-o como independente do contexto social. Dessa forma, o contato com a leitura e a escrita confere "poderes" aos sujeitos, no sentido de esse conseguir transitar em diversos contextos letrados, de forma autônoma.

Nesse sentido, parte-se do pressuposto de que a prática dessas habilidades permite ao indivíduo sua inserção em diversos eventos de letramento, adaptando-se à conjuntura de um letramento universal (KLEIMAN, 2008; ROJO, 2009; BUZATO, 2010; TFOUNI, 2010; STREET, 2014); há uma supremacia da tradição escrita em relação à oral, e a decodificação dos signos linguísticos torna-se uma prática autossuficiente para a inserção do sujeito na sociedade (TFOUNI, 2010).

Esse modelo de letramento - o mais utilizado na agência escolar centra-se em práticas homogêneas, de comunicação individual, não raro distanciadas de elementos culturais relevantes aos grupos minoritarizados que a ele têm acesso e evidencia uma cultura muitas vezes elitista, centrada nos cânones e na escrita como um elemento de poder. 
Em contrapartida, Street (2014) destaca o letramento modelo ideológico, que vê as práticas de escrita como associadas ao contexto social, cultural e à estrutura comunicativa da sociedade. As práticas sociais de leitura e de escrita funcionariam não como um mecanismo que promova a adaptação social do sujeito ao mundo e às suas exigências sociais, mas para o resgate identitário e construção de identidades fortes, para o empoderamento, em sua cultura local, de vozes que são silenciadas não apenas na agência escolar, mas em outros contextos sociais, e para uma contra-hegemonia global.

Assim, o trabalho em sala de aula com os multiletramentos oferece aos atores educacionais a possibilidade de inserirem-se em outras práticas discursivas presentes nas sociedades letradas (e não apenas no universo escolar) e a ampliar a circulação de gêneros textuais no universo escolar. Dentre esses gêneros, elegeu-se para esta discussão a narrativa fílmica.

\section{Narrativa fílmica como evento de letramento}

A narrativa é, para Todorov (1980, p. 62), um "gênero cuja característica predominante é o encadeamento cronológico e, às vezes, casual de unidades descontínuas". Constitui-se como um dinamismo integrador que tira uma história una e completa de diversos incidentes. Estrutura-se a partir da configuração de eventos narrados (macroestruturais), da trajetória das personagens e da sintaxe da narrativa (sequências narrativas). Apresenta, em sua constituição, uma natureza linguística intersemiótica, a partir das linguagens verbo-visual, não-verbal, gráfica e sonora; uma forma híbrida de gêneros textuais; sequências de eventos e/ou acontecimentos.

Essas características fazem parte de diversos tipos de narrativas na época atual, inclusive nas denominadas de narrativas fílmicas. Esse tipo de narrativa, por apresentar diversos elementos simbólicos, contribui para a polissemia de leitura textual, pois parte das experiências dos sujeitos e dos eventos de letramento dos quais esses já tenham participado. Assim, o sujeito interage de forma ativa na produção de significados dos textos (verbal, visual, sonoro etc.) que compõe essa narrativa. A partir dessas características, a 
narrativa fílmica - uma prática de letramento que envolve diversas ordens discursivas - constitui-se em um importante texto que deve ser trabalho na sala de aula pelo professor, a partir de um projeto didático que visualize não apenas ações que fazem parte do universo escolar, mas também as que norteiam a vida cotidiana dos alunos.

Por essas características, esse tipo de texto tornou-se ideal para o trabalho com práticas de letramento e oralidade no 4ㅇ ano do Ensino Fudamental I. Para a constituição da ação pedagógica, optou-se pela sequência didática (SD), por esse recurso possibilitar a organização lógicoestrutural das atividades, com vistas a atingir fins específicos de aprendizagem. A SD foi aplicada em cinco aulas de Língua Portuguesa. Pretendeu-se, com essa atividade, refletir sobre os multiletramentos e a necessidade de a escola promover, na atualidade, outras práticas de leitura, escrita e oralidade, tendo em vista que o texto apresenta-se a partir de outros suportes e com outros recursos semióticos.

\section{Sequência didática e práticas de letramento e oralidade: situando a narrativa fílmica na aula de língua portuguesa}

Sequência didática (SD) é um conjunto de atividades ligadas entre si, planejadas etapa por etapa, a partir de objetivos específicos e/ou competências a serem ensinados, organizadas pelo professor de acordo com as finalidades de aprendizagem a serem alcançadas pelos alunos. Corresponde a

\footnotetext{
um procedimento simples que compreende um conjunto de atividades conectadas entre si, e prescinde de um planejamento para a delimitação de cada etapa e/ou atividade para trabalhar os conteúdos disciplinares de forma integrada para uma melhor dinâmica no processo ensino-aprendizagem (OLIVEIRA, 2013, p. 53)
}

Entende-se, então, que a sequência didática é um conjunto de atividades escolares organizadas de maneira sistemática (DOLTZ ET AL, 2004); proporciona um conjunto de atividades que propicie a transposição didática 
adequada de conhecimentos (CRISTÓVÃO, 2009); representa um meio didático interativo (OLIVEIRA, 2013); tem como objetivo um ensino interdisciplinar (OLIVEIRA, 2013).

A elaboração da sequência didática narrativa fílmica partiu de algumas etapas definidas de trabalho, entre elas: negociação da proposta de trabalho entre a coordenadora (e a monitora) do projeto de extensão Letramento e Ensino, a professora e os alunos do 4 ano da escola selecionada; mapeamento do conhecimento prévio dos alunos e de suas necessidades educativas; análise de conteúdos atitudinais, procedimentais e conceituais a serem trabalhados a partir da narrativa fílmica; pesquisa sobre temas transversais à educação a serem incorporados na SD; elaboração de atividades individuais e em grupo e realização de avaliação da aprendizagem dos alunos.

A utilização da SD teve como principal objetivo facilitar o entendimento, por parte dos alunos, de conteúdos interligados, de forma interdisciplinar e inserir esse sujeito em novas situações de aprendizagem (JOSÉ, 2008), tendo como enfoque uma diversidade de ordens discursivas. Por ser um espaço que permite refletir sobre o fazer pedagógico, através do planejamento e da revisão de ações educativas e da interação entre professores e alunos, promovendo, assim, diversas situações de aprendizagem, a sequência didática representou um importante meio para a racionalização (comunicativa) da ação docente, a partir da conexão entre os multiletramentos que fazem parte da vida cotidiana e escolar das pessoas (imagem, som, música, texto escrito, texto falado etc.). Além disso, permitiu ao docente integrar atividades linguísticas aos contextos sociais e culturais de seus alunos.

\section{Desenvolvimento da sequência didática}

A sequência didática narrativa fílmica foi desenvolvida com alunos do 4o ano do Ensino Fundamental I, de uma escola pública, no município de Conceição do Coité, a partir do filme O Lorax: em busca da trúfula perdida, como parte das atividades do projeto de extensão Letramento e Ensino. Teve como objetivo incentivar os alunos a interpretarem e a significarem textos 
orais, escritos e imagéticos oriundos dessa narrativa, levando em conta eventos de letramento que fazem parte da experiência textual, social e cultural desses sujeitos.

As atividades de produção de sentido partiram de quatro eixos estruturantes do ensino de Língua Portuguesa - leitura, escrita, oralidade e análise linguística. A primeira etapa da SD teve como foco o desenvolvimento da oralidade dos alunos, a partir do reconto de sequências de eventos da narrativa fílmica $O$ Lorax. Nesse sentido, teve-se como ênfase a rememoração da história; reconhecimento da sintaxe do gênero narrativo; identificação dos diferentes códigos (verbal/visual/sonora), a partir da vivência efetiva com múltiplas linguagens; validação da coautoria dos alunos ao reconstruírem o enredo do filme.

O trabalho com a oralidade em sala de aula é uma das competências que se espera da escola por se tratar de um momento em que o professor oportuniza ao aluno não apenas a possibilidade de observar e analisar determinadas práticas orais, mas, também, a exercitar diferentes oralidades, na sala de aula e no ambiente extra-escolar, tendo em vista os contextos, as motivações, as finalidades para a produção desses textos.

Ao trabalhar com a oralidade a partir da narrativa fílmica, levou-se em consideração que essa habilidade se apresenta sob várias formas ou gêneros textuais fundados na realidade sonora; vai desde uma realização mais informal a mais formal nos mais variados contextos de uso; representa uma prática social interativa para fins comunicativos. Na sequência didática, foram propostas situações sistemáticas e organizadas de oralidade, de modo que o aluno aprendesse a organizar a própria fala, a partir da consideração das especificidades do contexto interativo e dos multiletramentos intrínsecos a esse processo.

A segunda atividade da SD levou em conta a produção de textos escritos e/ou imagéticos e análise linguística. Para isso, solicitou-se que os alunos registrassem, a partir do gênero cartaz, coisas (animadas e inanimadas) que faziam parte da narrativa fílmica. Pretendeu-se, nesse momento, o desenvolvimento de capacidades, como a conceituação do substantivo; sua identificação e agrupamento em categorias (próprios, comuns, simples, 
compostos); reconhecimento da potência nomeadora do signo linguístico; exploração das habilidades de observação e rememoração. Ao dialogar com os signos escritos e os imagéticos, os alunos tiveram a oportunidade de perceber que o texto, na atualidade, vem adquirindo outras configurações, sendo que, muitas vezes, transcendem a escrita, estruturando-se de forma multimodal.

Nesse sentido, "as imagens transformam-se em referências diretas ou indiretas da realidade física e social, sendo necessária uma escolha seletiva, tendo em vista que as sociedades usam imagens como um modo de legitimar argumentos e fatos relatados e descritos" (VIEIRA, 2015). Ao articular textos verbais e imagéticos, os alunos tiveram a oportunidade de refletir sobre a sintaxe das narrativas, que se desenvolve por processos associativos ou metafóricos, processos metonímicos, dentre outros, estabelecendo relação de sentido entres os modos textuais.

A terceira atividade realizada com a turma de 40 ano teve como objetivo contribuir com a construção do processo do texto escrito. Nesse momento, solicitou-se que os alunos apresentassem (por escrito) a ordem lógico-sequencial dos principais eventos constitutivos da narrativa, tendo em vista o desenvolvimento de aspectos inerentes a esse gênero, tais como: localização das ações dos atores que circulam nos universos textuais a partir de diferentes tempos e espaços; reconhecimento de categorias oriundas das narrativas info-juvenis (competência, desempenho e performance atribuídos às personagens; sanção ao antagonista da trama etc.); compreensão da relação intrínseca entre macro/microestrutura da narrativa; identificação da sequência, ênfase e ritmo como construtividade da narrativa.

Essa atividade contribuiu para que o aluno percebesse a escrita enquanto prática plural, culturamente sensível e significativa para a formação de sujeitos críticos e protagonistas em diversos espaços sociais (ROJO, 2008). Estruturou-se a partir da delimitação do contexto de produção (rememoração e atribuição de sentido da narrativa fílmica) e ao objetivo pretendido (visualizar a percepção de elementos norteadores do filme $O$ Lorax), ao espaço de circulação (em sala de aula/escola) e ao público a ser atingido (colegas da escola), ao suporte e ao gênero textual (cartaz ou jornal mural) a ser redigido. 
Por fim, a última atividade proposta na SD teve como objetivo ampliar o conhecimento dos alunos em relação à narrativa, tanto nas modalidades escrita e oral, levando-os a compreender as especificidades de cada uma delas. Para isso, propôs-se a exploração dos aspectos diferenciais entre os tipos de expressão narrativa (oral e escrita); reconhecimento da presença de unidades descontínuas na narrativa; localização dos incidentes que compõem o conjunto da narrativa. Essa sequência de atividades levou em conta princípios estruturadores da narrativa quanto aos eventos narrados (macroestrutura), à trajetória das personagens e à sintaxe da narrativa.

A sequência didática (e seus eventos de letramento) constituiu-se em uma prática de letramento importante na aula de Língua Portuguesa. Representou ocasião em que, nas interações humanas, a língua escrita está presente e exerce algum papel (STREET, 1988; 2003). Dessa forma, tornou-se uma importante prática docente para a ampliação das competências de leitura, escrita e oralidade dos alunos. Contribuiu para a inserção desses alunos em um contexto multiletrado.

\section{Considerações finais}

O ensino de Língua Portuguesa na Educação Básica deve centrar-se em ações educativas que possibilitem aos estudantes ampliarem seus conhecimentos linguísticos e comunicativos, a partir de situações contextualizadas e significativas não apenas no espaço escolar, mas, também, em outras esferas sociais. Nesse sentido, espera-se que as escolas, na atualidade, promovam atividades pedagógicas que levem em conta práticas e eventos de letramento diversificados, capazes de desenvolver nos alunos capacidades de leitura, escrita e oralidade necessárias para a inserção desses sujeitos em diversas esferas públicas na contemporaneidade.

Nesse sentido, os multiletramentos e suas implicações na vida social, escolar, pessoal, cultural, econômica etc. desses alunos devem ser o ponto de partida das ações de ensino de linguagem. Assim, espera-se que o professor reestruture seu projeto didático de modo a considerar a diversidade cultural e linguística do mundo atual, levando-se em conta as modalidades de 
linguagem, para a formação de sujeitos produtores ativos de textos (orais e escritos), que dialoguem com a diversidade de ordens discursivas.

\section{Referências}

BARTON, David; HAMILTON, Mary. Local literacies: reading and writing in one community. London: Routlege, 1998. Trad. livre.

BAZERMAN, Charles. Escrita, Gênero e Interação Social. São Paulo: Cortez Editora, 2007.

BRASIL, Ministério da Educação e do Desporto. Secretaria de Educação Fundamental. Parâmetros Curriculares Nacionais: língua portuguesa. Brasília, 1997.

BUZATO, Marcelo. Novos letramentos e apropriação tecnológica: conciliando heterogeneidade, cidadania e inovação em rede. In: RIBEIRO, Ana Elisa. (Org.). Linguagem, tecnologia e educação. São Paulo: Petrópolis, 2010.

COPE, B.; KALANTZIS, M. Multiliteracies: literacy learning and the design of social futures. London: Routldge, 2000.

DIAS, Reinildes. Web Quests. Tecnologias, multiletramentos e a formação do professor de inglês para a era do ciberespaço. Revista Brasileira de Linguística Aplicada. Belo Horizonte, 2012.

DIONÍSIO, Ângela P. Gêneros multimodais e multiletramento. In: KARWOSKI, Acir M; GAYDECZKA, Beatriz; BRITO, Karim S. (Org.). Gêneros textuais: reflexões e ensino. Rio de Janeiro: Lucerna, 2005.

GARCÍA-CANCLINI, N. Culturas híbridas - Estratégias para entrar e sair da modernidade. São Paulo: EDUSP, 2008[1989].

HABERMAS, Jürgen. Teoria do agir comunicativo. racionalidade da ação e racionalização social. Trad. Paulo Astor Soethe. São Paulo: Editora WMF Martins Fontes, 2012.

KLEIMAN, Ângela. Preciso "ensinar" o letramento? Não basta ensinar a escrever? Brasília: Ministério da Educação, 2005.

KELIMAN, Angela (Org). Os significados do letramento: uma nova perspectiva sobre a prática social da escrita. 10 reimpressão. Campinas: Mercado de Letras, 2008. 
OLIVEIRA, Maria Marly de. Sequência Didática Interativa no processo de formação de professores. Petrópolis, Rio de Janeiro: Vozes, 2013.

ROJO, Roxane. Letramentos múltiplos, escola e inclusão social. São Paulo: Parábola, 2009.

ROJO, Roxane. Gêneros de discurso/texto como objeto de ensino de línguas: um retorno ao trivium? In: SIGNORINI, Inês (Org.). [Re]discutir texto, gênero e discurso. São Paulo: Parábola, 2008.

SOUSA, Jesus Maria. Educação: textos de intervenção. Portugal: O liberal, 2004.

STREET, Brian. Letramentos sociais: abordagens críticas do letramento no desenvolvimento, na etnografia e na educação. Trad. Marcos Bagno. São Paulo: Parábola Editorial, 2014.

TFOUNI, Leda Verdiani. Letramento e alfabetização. 9 ed. São Paulo: Cortez, 2010.

TODOROV, Tzvetan. Introdução à literatura fantástica. São Paulo: Perspectiva, 1980.

VIEIRA, Josenia. Multimodalidade e eventos de letramento. In: VIEIRA, Josenia; SILVESTRE, Carminda. Introdução à multimodalidade: contribuições da gramática sistêmico-funcional, análise de discurso crítica e semiótica social. Brasília: J. Antunes Vieira, 2015.

Recebido em 13 de novembro de 2016.

Aceito em 2 de dezembro de 2016. 